\title{
Payments for Ecosystem Services in the Context of Adaptation to Climate Change
}

Isabel van de Sand $^{1}$

\begin{abstract}
The concept of payments for ecosystem services (PES) has recently emerged as a promising tool for enhancing or safeguarding the provision of ecosystem services (ES). Although the concept has been extensively scrutinized in terms of its potential positive and negative impacts on the poor in developing countries, less attention has been paid to examining the role of PES in the context of adaptation to climate change. PES has some potential to contribute to adaptation to climate change, but there are also risks that it could undermine adaptation efforts. In order to maximize synergies and minimize trade-offs between PES and adaptation, it is important that the conceptual links between both are made explicit. The present article presents the main conceptual links between PES and adaptation to climate change and suggests ways of making PES pro-poor and proadaptation. Drawing upon the concepts of vulnerability, adaptive capacity, and socioecological systems, it is suggested that PES can potentially contribute to adaptation in three main ways: through enhancements in the provision of ecosystem services, by enhancing adaptive capacity in the way PES is designed and implemented, and by providing an incentive mechanism to adopt specific measures for adaptation to climate change. Reflecting on the lessons from the PES and poverty literature, the article suggests ways to make PES pro-poor and pro-adaptation and concludes with further research needs in this area.
\end{abstract}

Key Words: adaptation; adaptive capacity; climate change; ecosystem services; payments for ecosystem services; payments for environmental services; vulnerability

\section{INTRODUCTION}

The concept of payments for ecosystem services (PES) has recently emerged as a promising tool for enhancing or safeguarding the provision of ecosystem services (ES). PES establishes an incentive mechanism through which ES beneficiaries pay ES providers for the provision of these services. Although the concept has been extensively scrutinized in terms of its potential positive and negative impacts on the poor (e.g., Suyanto et al. 2007, Bulte et al. 2008), less attention has been paid to examining the role of PES in the context of adaptation to climate change.

There are a number of possible reasons why adaptation has not featured more prominently in the literature on PES. First of all, adaptation to climate change is a relatively new concept, which has long been neglected in the climate change arena as more attention has been paid to mitigation (Burton et al. 2002, Dang et al. 2003, Horstmann 2008, Zelli 2010). This has only recently changed - with adaptation taking on a much more prominent role both in terms of academic research as well as in the policy arena-as awareness about the need for adaptation has slowly increased. Nevertheless, the concept of adaptation remains vague, making it difficult to implement in practice (Horstmann 2008). Consequently, the process of mainstreaming adaptation into public and sectoral policies is only just beginning. Second, the concept of PES itself is also relatively young (Wunder 2008, Pattanayak et al. 2010), with the first PES schemes in developing countries having been initiated during the 1990s (Pagiola 2008). As such, much of the literature on PES has focused on the effectiveness of the instrument and success and limiting factors when putting it into practice (e.g., Engel et al. 2008) as well as its potential role in poverty reduction (e.g., Bulte et al. 2008). Including another complex dimension at a time when the instrument itself was still being developed and tested may simply have been too soon. As lessons from the first generation of PES projects are now emerging and as the need for adaptation to climate change becomes clearer and more accepted among policy makers and development practitioners, the links between PES and adaptation to climate change should be explored in greater depth.

Considering PES in the context of adaptation to climate change is important for a number of reasons. In addition to a wide range of stressors that have contributed to the degradation of ecosystems and the services they provide, climate change presents an additional threat (Millennium Ecosystem Assessment 2005). As the article will show, PES has the potential to reduce the vulnerability of the ecosystem and the actors dependent on it, but there are also potential trade-offs. Analyzing the synergies and trade-offs between PES and adaptation to climate change is thus important in order to avoid PES contributing to maladaptation. Furthermore, although there are some overlaps, poverty reduction and vulnerability reduction are not the same; therefore, blanket assumptions that PES contributes through poverty reduction to adaptation to climate change do not necessarily hold true (Eriksen et al. 2007). Nevertheless, in the light of scant financial resources available for poverty reduction, adaptation to climate change, and conservation of natural resources, maximizing synergies 
among these areas is important in order to advance toward the greater goal of sustainable development and to avoid unnecessary competition between practitioners and researchers focusing on PES and adaptation to climate change, respectively.

This article argues that there is great potential but also several challenges that need to be overcome in order to foster a greater integration of PES and adaptation to climate change. Building upon the work of van de Sand (2004) and Willetts (2008), who were among the first to propose that payments for watershed services could potentially contribute to adaptation to climate change in a watershed in Indonesia and Rwanda, respectively, the article starts by presenting the main conceptual links between PES and adaptation to climate change. The framework on vulnerability in sustainability science by Turner et al. (2003), which was further developed by Locatelli et al. (2008) in the context of ES, thereby serves as a reference point. The following sections discuss in greater detail the new dimension that adaptation to climate variability and change brings to the already discussed relationship between poverty and PES. In addition, the article reflects on lessons learned from the PES and poverty debate for making PES "proadaptation" and concludes by spelling out further research needs in this area.

Although PES-type mechanisms also exist in developed countries, the focus of this article is on developing countries, as these are generally considered to be especially vulnerable to climate change because of their greater sensitivity and lower adaptive capacity (Smith et al. 2001, Schneider et al. 2007).

\section{CONCEPTUAL FOUNDATIONS}

Before the conceptual link between PES and adaptation to climate change is described, the following two sections present a short overview of the concepts of PES and adaptation to climate change.

\section{The Concept of Payments for Ecosystem Services}

Payments for ecosystem (or environmental services) have been defined as:

a voluntary transaction in which a well-defined
environmental service (or land-use likely to secure
that service) is being 'bought'by a (minimum of one)
ES buyer from a (minimum of one) ES provider if
and only if the provider continues to supply that
service (conditionality) (Wunder 2005).

The definition provided by Wunder is conceptually based on the Coase theorem (Engel et al. 2008, Gómez-Baggethun et al. 2010, Muradian et al. 2010) by seeking to internalize the positive externalities that ES provide through bargaining solutions between those who provide the services and those who gain from it and is theoretically rooted in the field of environmental economics (Gómez-Baggethun et al. 2010).
Although the theoretical usefulness of Wunder's definition is generally acknowledged, its relevance for practical purposes is increasingly contested. As experience in the implementation of PES grows, it has become increasingly clear that only a limited number of projects meet all the requirements of the definition, a fact that is also acknowledged by Wunder himself (Wunder et al. 2008). As such, revised conceptual frameworks have recently emerged that relax some of Wunder's criteria and put a greater emphasis on PES as an incentive mechanism (Sommerville et al. 2009, Muradian et al. 2010).

Literature on PES typically distinguishes between four different kinds of services for which payments are made: hydrological or watershed services, carbon sequestration, biodiversity protection, and landscape beauty (e.g., LandellMills and Porras 2002, Wunder 2005). In addition, certification of products is also sometimes included as a form of PES (see, e.g., Food and Agriculture Organization (FAO) 2007, Carroll and Jenkins 2008) although others do not consider it to be a PES as certification requirements often do not entail guaranteed price premiums for certified products (for example, Sommerville et al. 2009). As noted by Ravnborg et al. (2007), this categorization differs from the more functionally oriented classification provided in the Millennium Ecosystem Assessment (MEA), which has become one of the most widely used classification systems (Fisher et al. 2009). The MEA differentiates between provisioning services, such as food, water, fuel, and fiber; regulating services, such as climate, flood, and disease regulation, as well as water purification; supporting services, such as nutrient cycling and soil formation; and cultural services, including aesthetic, spiritual, educational, and recreational services (Millennium Ecosystem Assessment 2005). Apart from carbon sequestration, payments are thus not necessarily made for the direct provision of the ES, but for management or land-use practices that are expected to enhance or secure the service, as is also evident in Wunder's definition. Biodiversity, for example, is not an ES itself, but the establishment of, e.g., conservation areas to protect biodiversity through a PES scheme can contribute to enhanced cultural, regulating, and provisioning services.

Apart from differing in terms of the environmental services they provide, the different PES schemes can also be differentiated according to the scale at which they operate (Ravnborg et al. 2007). Whereas PES for hydrological services primarily operate at the local or regional scale, buyers for biodiversity, landscape beauty, and carbon sequestration are often located abroad, with PES schemes spanning international boundaries.

\section{The Concept of Adaptation to Climate Change}

The concept of adaptation has its roots in evolutionary biology, but has also been adopted by the social sciences to describe adaptations in human systems to environmental and other 
types of stresses (cf. Smit and Wandel 2006). In the context of climate change, adaptation is used both for human and natural systems. The Intergovernmental Panel on Climate Change (IPCC), for example, defines adaptation as "adjustments in natural or human systems in response to actual or expected climatic stimuli or their effects" (McCarthy et al. 2001:982). The concept of adaptation to climate change has been elaborated with the help of other concepts, including vulnerability, adaptive capacity, and resilience (e.g., Smit and Wandel 2006, Horstmann 2008).

In general, adaptations are expected to reduce vulnerability (Pielke 1998, Adger et al. 2004, Smit and Wandel 2006).

The concept of vulnerability has its roots in a number of different scientific disciplines, leading to a multitude of different interpretations and definitions of the concept (e.g., Füssel 2007). Nevertheless, there are some common elements, as a number of reviews on the concepts of adaptation, adaptive capacity, and vulnerability have shown (e.g., Adger 2006, Smit and Wandel 2006). These include the conceptualization of vulnerability in terms of exposure, sensitivity, and adaptive capacity. This is also reflected in the IPCC Assessment Reports, which define vulnerability as "a function of the character, magnitude, and rate of climate variation to which a system is exposed, its sensitivity and its adaptive capacity" (McCarthy et al. 2001:995). Exposure refers, in that definition, to the "nature and degree to which a system is exposed to significant climatic variations." Sensitivity relates to "the degree to which a system is affected, either adversely or beneficially, by climate-related stimuli" and adaptive capacity is defined as the "the ability of a system to adjust to climate change (including climate variability and extremes) to moderate potential damages, to take advantage of opportunities, or to cope with the consequences" (McCarthy et al. 2001, Parry et al. 2007).

Adaptive capacity has been further conceptualized through the description of its determinants. These include technological resources, human capital, social capital, the structure of institutions, managerial abilities of decision makers, the availability and access to financial and informational resources, and the public's perception of climate change (Brooks 2003). A further distinction has been made between generic and specific determinants of adaptive capacity. Health, income, and education, for example, are considered as generic determinants, whereas institutions, knowledge, and technology are specific determinants of climate impacts (Brooks 2003, Adger et al. 2007).

Adaptive capacity thus forms the main element that links adaptation and vulnerability together. Smit and Wandel (2006:286), for example, regard adaptation as "manifestations of adaptive capacity" that "represent ways of reducing vulnerability." Similarly, Adger et al. (2004:34) maintain that reductions in social vulnerability can be achieved "from the realization of adaptive capacity as adaptation." The term "realization" is important in this regard as the presence of adaptive capacity is no guarantee that adaptation will actually take place (e.g., Burton et al. 2001). It can thus be regarded as a prerequisite or potential for rather than actual adaptation (Brooks 2003). Factors that facilitate this realization are the recognition of the need for adaptation, the belief that adaptation is possible and desirable, the willingness to undertake adaptation, the availability of resources necessary for the implementation of adaptation strategies, and the ability to deploy resources in an appropriate manner (Adger et al. 2004).

\section{MAIN CONCEPTUAL LINK BETWEEN PES AND ADAPTATION TO CLIMATE CHANGE}

Adopting the conceptualization of Adger et al. (2004) and Smit and Wandel (2006), who regard adaptation as "ways of reducing vulnerability," it follows that, in order for PES to make a meaningful contribution to adaptation, it has to reduce vulnerability.

In line with most of the literature on global environmental and climate change, I conceptualize vulnerability in terms of its three main components: exposure, sensitivity, and adaptive capacity. Vulnerability can thus be decreased by enhancing adaptive capacity or reducing sensitivity, as I assume that exposure cannot be influenced at the local level. When speaking about vulnerability, it is always important to define who or what is vulnerable to what, i.e., delineating the system of analysis and its attributes (Füssel 2007). In the context of PES, the system of analysis is the coupled socioecological system.

Turner et al. (2003) have developed a useful framework for analyzing the vulnerability of socioecological systems, which has been further developed by Locatelli et al. (2008) in the context of ES. The framework features the coupled socioecological system in terms of its subcomponents, the natural system and the social system, which are linked through the provision of ES. A modified version of the framework is presented in Fig. 1, which also presents the PES actors as well as the different scales at which PES systems operate.

The social system in the context of PES is characterized through the interaction between ES buyers, ES providers, intermediaries, and non-participants of the scheme and the institutional arrangements in which they take place.

The natural system is characterized by the ecosystem that provides the services. Given the interdependence between the social and the natural systems (e.g., Giddings et al. 2002), I depict the social system as being embedded in the natural system.

Both systems are exposed to a range of stressors, including climate variability and change as well as other types of stressors. The impact that these stressors have on the coupled 
Fig. 1. Conceptual link between PES, adaptation, and vulnerability of the coupled socioecological system. Source: own illustration, based on Locatelli et al. (2008) and Turner et al. (2003). For reasons of simplicity, the figure only depicts the social system in terms of buyers and providers.

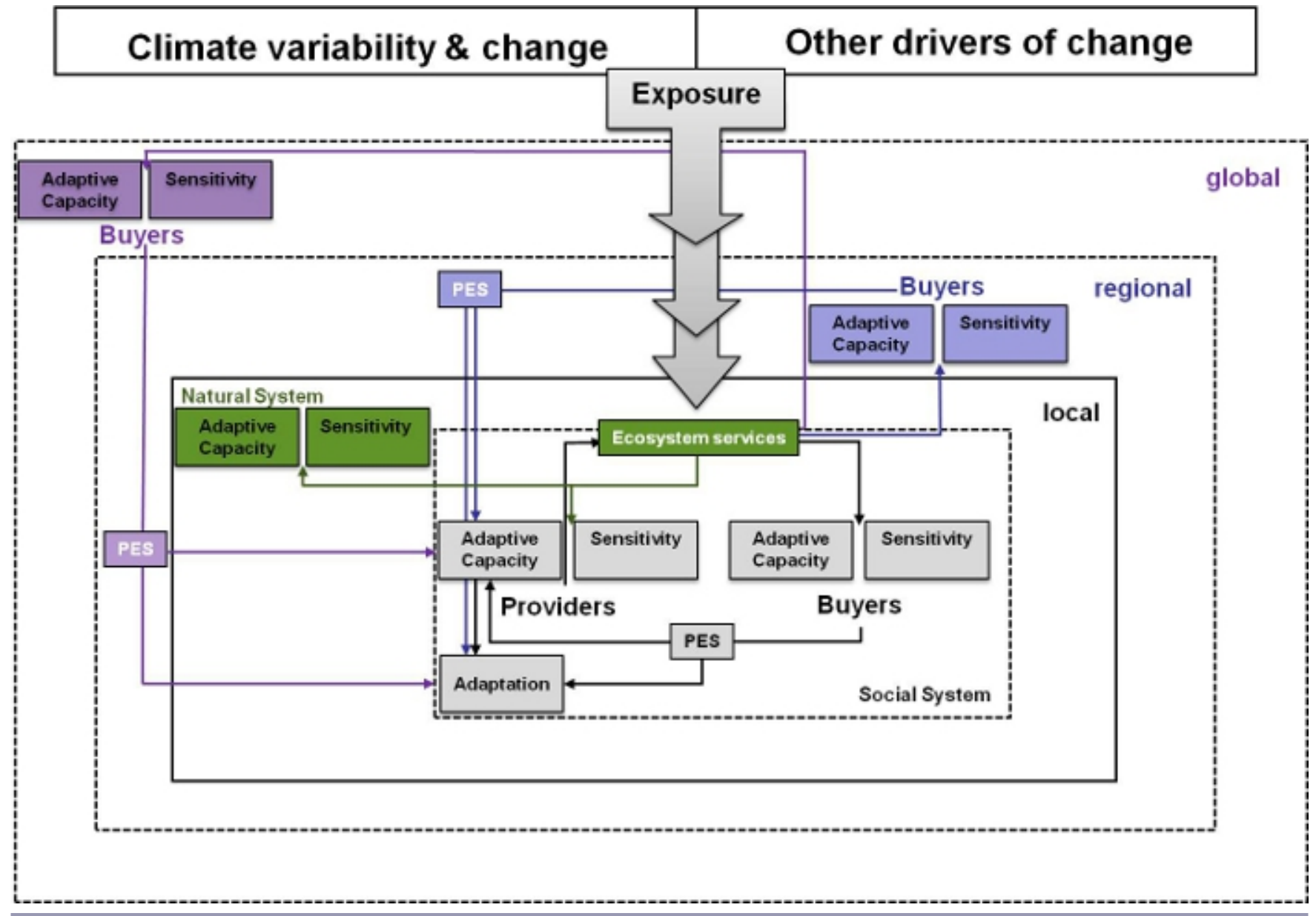

socioecological system depends on the adaptive capacity and the sensitivity of the various system components. These may vary substantially both within and between different kinds of PES systems, partly depending on the scale at which PES systems operate. For PES systems that operate primarily at the local level (such as many watershed PES), one might expect that both buyers and providers are exposed to similar kinds of stresses. Buyers, providers, and intermediaries of PES systems who operate at the regional or global scale (such as carbon and biodiversity conservation), however, are exposed to a different set of both climatic and non-climatic stresses, which further complicates the analysis.

There are three main ways in which PES and adaptation to climate variability and change interact. First, the provision of ES through PES could reduce the vulnerability of the coupled socioecological system and its various system components. Second, the PES scheme could increase the adaptive capacity of the various system components through the ways in which it is implemented and designed. Third, the PES could act as an incentive mechanism for ES providers to promote specific adaptation measures to climate variability and change.

\section{Linking PES and adaptation through the provision of ecosystem services}

The conceptual link between ES provision and the vulnerability of the socioecological system to climate change has already been made in the literature. Using the MEA's classification of ES, Locatelli et al. (2008) have shown that most ES relate to vulnerability through their influence on the elements of adaptive capacity and sensitivity. The various kinds of ES thereby play different roles.

Regulatory services, such as water regulation, erosion regulation, or natural hazard regulation, for example, can to some extent buffer the natural and the social system against the impacts of changes in climate and weather extremes (such 
as floods and droughts) (Millennium Ecosystem Assessment 2005), although much depends on local biophysical conditions. Provisioning services (e.g., food and fodder from natural sources) also have the potential to reduce the impacts of extreme events (Locatelli et al. 2008) by providing an alternative source of food and income. Cultural services contribute to the health and good social relations constituents of well-being (Millennium Ecosystem Assessment 2005) and thus contribute to adaptive capacity of the social system (Millennium Ecosystem Assessment 2005, Locatelli et al. 2008). The provision of ES thus mainly contributes to reducing vulnerability to climate variability and change at the local and regional levels.

The extent to which ES providers and buyers benefit from this vulnerability reduction varies according to their dependence on the service and the purpose for which the ES is enhanced. Providers who do not live in flood-prone areas of a watershed, for example, are less sensitive to the impacts of floods and will thus not directly benefit from water regulatory services. The enhanced provision of a single service can also lead to disadvantages at the local level, as there are often trade-offs involved in enhancing different ES for different purposes (Chan et al. 2006). An often-cited example for such trade-offs is the establishment of fast-growing tree species, such as eucalyptus for carbon sequestration, which might not only replace more biodiversity-rich habitat but could also have implications for the water table, thus increasing the sensitivity of the system to drought. Corbera and Brown (2010) also found that, in some carbon forestry projects that they reviewed, access to grazing land was restricted and degradation of soil and vegetation occurred. Thus, although some ES were increased, other parts were eroded, thereby potentially increasing rather than decreasing the vulnerability of those dependent on the services to climate variability and change.

\section{Linking PES and adaptation through its influences on adaptive capacity}

Apart from strengthening the natural asset base part of adaptive capacity through the provision of ES, PES could strengthen the adaptive capacity of buyers and providers through the way in which PES is implemented and designed. van de Sand (2004) and Willetts (2008) have established this conceptual link between adaptive capacity and PES in the case of local watershed-type PES in Indonesia and Rwanda, respectively. By comparing several determinants of adaptive capacity (institutions, knowledge, access to financial resources, poverty) with features likely to evolve during the development of watershed markets (establishment of institutional structures, generation of financial resources, targeting of the poor, generation of knowledge between water and land-use links, involvement of stakeholders, and conflict resolution), van de Sand (2004) has shown that payments for watershed services can potentially increase adaptive capacity. Similarly, Willets (2008) identified improved environmental management and monitoring, strengthened local economies, improved social capital and support for legal frameworks, and increased human capital as features of adaptive capacity that could possibly be strengthened during the set-up of a PES scheme in a watershed in Rwanda.

Although not under the heading of adaptive capacity, the literature on poverty and PES discusses the potential positive and negative implications of PES on livelihood assets (natural, physical, human, social, political, and financial assets) (see, e.g., Tacconi et al. 2010a), which partly correspond to the generic determinants of adaptive capacity. In addition to the benefits already mentioned above, others include improved health due to improvements in water supply and air quality and improvements in infrastructural development if payments are made at the community level. Risks include, among others, limited access to natural resources that result from certain landuse restrictions, indirect detrimental effects on nonparticipants in the scheme through increases in land value, inequitable access to financial resources, and capacity development components of PES, which could contribute to increased conflicts between participants and non-participants in the scheme, thus eroding social capital (Tacconi et al. 2010a). Furthermore, there is also the risk that the situation of PES providers may deteriorate as a result of their participation. In general, the voluntary criteria of PES assumes that ES providers will not be worse off than before the deal unless they have been cheated or have underestimated the effects of the deal (Wunder 2008). There are other voices in the literature, however, that challenge this assumption, especially with regard to the poor as providers of ES. Muradian et al. (2010:1204), for example, warns that, in some cases, the conditions of poverty may draw the poor to participate in PES schemes so that "the concept of free agency ... may in reality become 'forced trade' instead." Another concern that is often raised is that PES may result in a poverty trap or lock in, which results from the partly long-term prescribed forms of land use that limit the providers from engaging in alternative land uses (Karsenty (2004) cited in Wunder 2006, Muradian et al. 2010).

These risks are also important in the context of adaptation to climate change. If a PES schemes restricts the use of natural resources that form part of traditional adaptation strategies, this could increase the vulnerability of the various actors to climate variability and change. In addition, the long-term nature of many PES contracts may prevent ES providers from implementing certain adaptation strategies that would involve changing land-use practices (e.g., crop diversification or moving out of agriculture altogether).

\section{Linking PES and adaptation through incentivizing adaptation measures}

In addition to the links described above, PES could also provide an incentive mechanism for adopting specific 
adaptation measures to climate change. In many cases, the ability of poor rural dwellers to implement adaptation activities is constrained, thus limiting the possibility of autonomous adaptation. If ES providers see the need for and are willing to undertake adaptation measures, yet lack the appropriate means for implementation, there is thus an opportunity to tailor PES compensation in such a way that it provides direct incentives for adaptation measures. Instead of using cash payments, compensation could, for example, take the form of drought-resistant seeds as an adaptation measure against drought or climate variability more generally. In fact, reviews of PES schemes have shown that compensation for the provision of ES is often made in kind, in addition to or instead of using cash payments (e.g., Porras et al. 2008, Wunder et al. 2008), suggesting that non-financial benefits are also an important incentive for ES providers to join a PES deal. There are also, however, potential trade-offs between the implementation of certain adaptation measures and the enhancement of ES provision. The use of agro-chemicals to deal with the increased occurrence of pests and diseases resulting from climate change, for example, is likely to have implications both in terms of water quality as well as biodiversity-related services. Much, of course, depends on the biophysical characteristics of the system, making local-level assessments important.

\section{DISCUSSION}

Although it has long been lamented that there is still insufficient empirical evidence for the link between PES, livelihoods, and poverty reduction (e.g., Engel et al. 2008), more recent studies have tried to fill this gap, which also allows us to gain some more insights about the relationship between PES and adaptive capacity. Using a comparative case-study analysis of nine PES schemes from Africa, Asia, and Latin America, Tacconi et al. (2010b) looked at the impacts of PES on livelihood assets. Results from these case studies suggest that there have been enhancements in terms of social, human, and physical capital, whereas the impact on financial and natural capital seems to be more mixed. Social capital, for example, has been enhanced through strengthening local institutions, improving coordination capacity, and facilitating links to other actors such as local government. Advances in human capital relate to increased capacity building in environmental awareness, agro-forestry practices, and land management among others. In some cases, physical capital was improved in terms of water supply, schools, roads, and clinics as payments were made to community institutions. Where payments have been made to individual farmers, a critical issue that emerged from the review is that, in many cases, payments were not based on the opportunity costs of ES providers and often tended to diminish over time, thus risking the long-term sustainability of the scheme. Furthermore, payments were found to constitute only a small proportion of household income. In terms of natural capital, only small improvements could be observed, although the evidence that these resulted from the implementation of the PES scheme remained limited. The findings echo those of a recent review on PES and watershed services, where many cash payments were also found to present a low share of opportunity costs and household income, and evidence that hydrological services were actually delivered was often found to be lacking (Porras et al. 2008). This is partly due to a lack of rigorous impact evaluations carried out on PES projects (Pattanayak et al. 2010, Caplow et al. 2011). Especially in the case of hydrological services, there is still considerable scientific uncertainty concerning the impacts of changes in land use in tropical watersheds on hydrology (especially water quantity), and myths or misconceptions concerning water and forest links still prevail (Tognetti et al. 2003, Bruijnzeel 2004, Kosoy et al. 2007, Porras et al. 2008, Locatelli and Vignola 2009). Biodiversity PES schemes also face challenges in identifying and disentangling ES because of the complexity and encompassing nature of biodiversity itself (Kosoy and Corbera 2010). In many cases, PES schemes are thus built on proxies rather than actual services, which makes monitoring and evaluation difficult (Corbera et al. 2009, Kosoy and Corbera 2010). Although this may be fine from a precautionary point of view, it could contribute to maladaptation in the long run if payments are based on false perceptions or if critical links between ES and functions are overlooked.

There is thus limited evidence that PES can contribute to enhanced generic adaptive capacity. Simply strengthening certain livelihood assets does not, however, necessarily mean that the adaptive capacity will be sufficiently strengthened to deal with specific impacts of climate variability and change or that adaptive capacity will be realized as adaptation. If knowledge about specific impacts of climate change or about the technology to implement certain adaptation measures (that is, the specific determinants of adaptive capacity) is lacking, increases in knowledge in other areas (ES provision, agroforestry, etc.) will only be of limited help. Although it is unlikely that PES will automatically contribute to enhancements in specific adaptive capacity, the institutional structures developed during the set-up of a PES scheme could probably be used to enhance specific adaptive capacity and to realize adaptive capacity as adaptation. This could be done, for example, by facilitating knowledge transfer on the impacts of climate variability and change and training on the implementation of certain adaptation activities. In this way, current forms of "pro-poor PES" would be moved toward "proadaptation PES."

Building on the definition of pro-poor PES, which seeks to maximize the potential positive and minimize the potential negative impacts of PES on the poor (Pagiola 2007), a proadaptation PES should maximize the potential synergies and minimize the potential trade-offs between PES and adaptation. Pro-adaptation PES is thus not meant to replace but rather to build upon and complement pro-poor PES. 
Fig. 2. Adaptation as a continuum. Source: adapted from McGray et al. (2007) and Klein (2010)

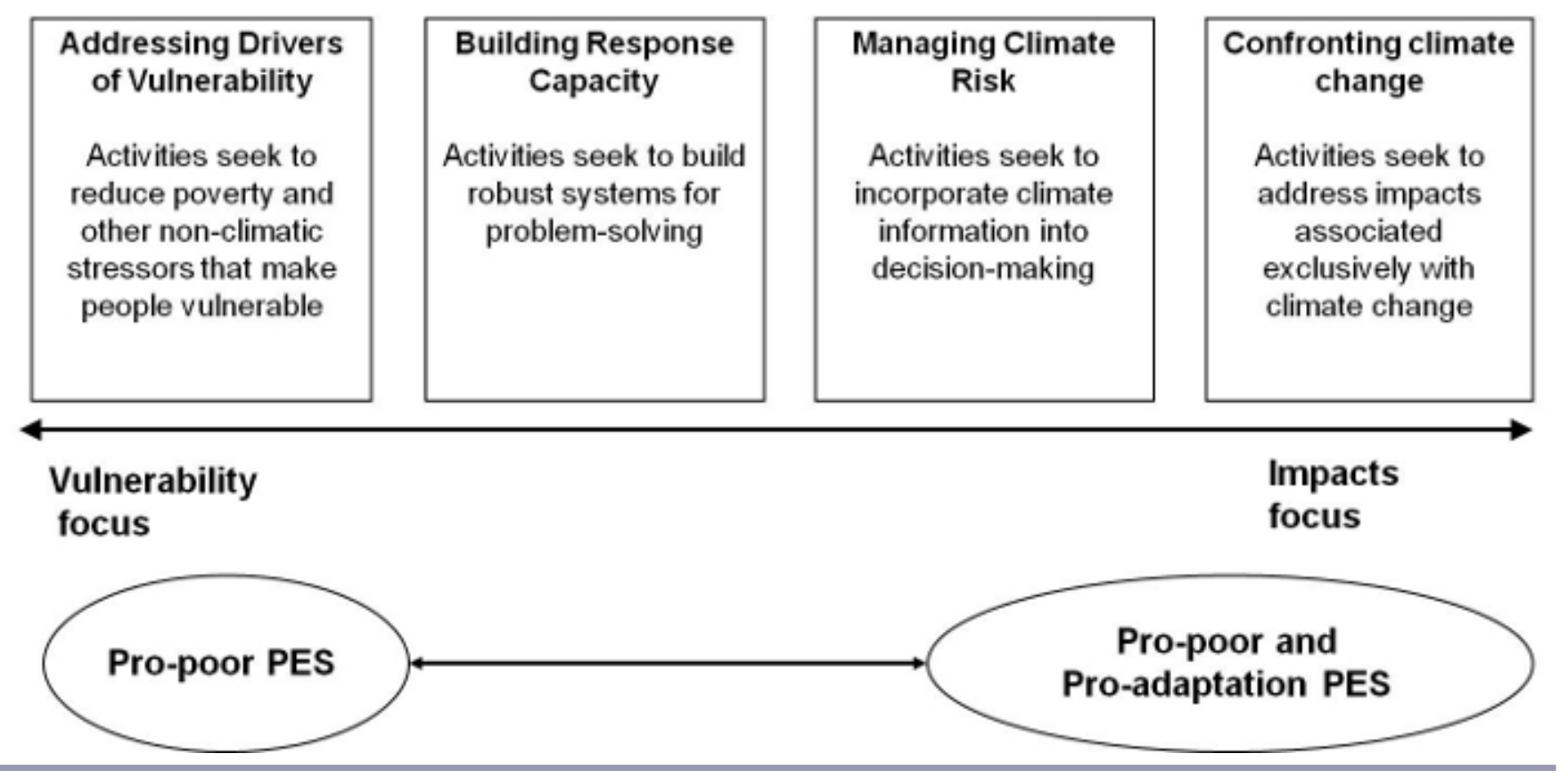

The conceptualization of McGray et al. (2007) might help to visualize what is meant by such a move. McGray et al. (2007) conceptualize adaptation activities as a continuum ranging from activities that primarily address the underlying drivers of vulnerability without considering the impacts of climate change on the left-hand side to those with a purely impact focus at the far right-hand side of the continuum (see Fig. 2). From a theoretical point of view, pro-poor PES can be positioned toward the left of the figure, given its potential to improve the livelihoods of poor ES providers and to develop a more robust system through the provision of ES. From a practical point of view, however, the position is much less clear. In addition to the fact that impacts on livelihoods, although positive, are more modest than expected (e.g., Porras et al. 2008, Wunder et al. 2008), there is also as of yet still limited scientific evidence that PES delivers more ES than would occur without the intervention (Pattanayak et al. 2010). Firmly embedding PES in such a position would thus require improving the links between PES and livelihoods and increasing the scientific evidence in support of land use and ecosystem provision links, both of which have also been identified as fundamental needs for the further development of PES schemes more generally.

Apart from embedding PES in such a position, there is also a greater need to take climate variability and change into account, thereby moving PES more toward the right of the spectrum, thus making PES pro-poor and pro-adaptation.
The identification and maximization of synergies and minimization of trade-offs between PES and adaptation would thus require:

- Taking into account the impacts of climate variability and change on the various actors (ES providers, ES buyers, non-participants in the scheme) and the provision of ES;

- An analysis of the adaptive capacity of the actors in order to identify which elements of adaptive capacity need enhancement and how these would be impacted through the implementation of the PES scheme;

- An analysis of current and potential adaptation strategies of the actors and their potential implications for ES provision; and

- An evaluation of the costs needed to implement adaptation and PES measures.

In striving to make PES pro-poor and pro-adaptation, several challenges need to be overcome, which are partly related to the theoretical foundation of the PES concept and conceptual differences between PES and adaptation.

\section{Trade-off among different objectives of PES, pro-poor PES, and pro-adaptation PES}

Some of the arguments that have been made in the PES and poverty debate are that PES is primarily an economic instrument and that the main focus should be on the provision 
of ES and not on other objectives, such as poverty reduction (e.g., Pagiola et al. 2005, Pagiola 2007, Wunder 2008). The main reason behind this argument is that targeting the poor for ES provision could undermine the effectiveness of the scheme, as the poor do not necessarily live in those areas that provide the most services. There is thus a potential trade-off between targeting poor ES providers and targeting ES providers who provide the most services.

The trade-off between maximizing ES provision and targeting actors for other objectives also holds in the case of PES and adaptation. Just as targeting the poor as ES providers might undermine the effectiveness of the scheme, so could targeting the most vulnerable actors or areas in the socioecological system.

In describing the links between PES and adaptation above, most of the attention has been placed on the actors within the PES system. This is related to the concept of ES itself, which equates ES to the benefits that humans derive from ecosystems (Millennium Ecosystem Assessment 2005). Nevertheless, the question remains in what way should a pro-adaptation PES not only contribute to the adaptation of the social system but also to the adaptation of the natural system. Redford and Adams (2009), for example, argue that just focusing on those services that increase human well-being fails to take into account and might even inhibit other ecosystem processes that are vital for the long-term functioning of the natural system. Giving the examples of diseases, droughts, floods, and fire, which are in general regarded as being detrimental to human well-being but perform important regulatory services for natural systems, they show that there can be substantial tradeoffs between managing regulatory services for human and natural systems, which could thus lead to increased vulnerability of the latter. According to Kosoy and Corbera (2010:1232), the fact that many PES schemes focus on single services and itemize them for marketing purposes "contributes to veil important ecosystem interactions and reduces our perception of what actually an ecosystem is and how it functions." Such an understanding, however, is vital in order to uncover the relationship between changes in the provision of ES and the vulnerability of the coupled socioecological system to climate variability and change.

\section{Overcoming the trade-off}

Within the poverty and PES literature, this trade-off has to some extent been circumvented by setting guidelines for the establishment of pro-poor PES. These include evaluating the positive and negative impacts on the poor, encompassing the poor as ES providers and ES buyers, in addition to the indirect impacts on poor non-participants in the scheme (Pagiola 2007, Wunder 2008). Other elements of the guidelines for implementing pro-poor PES include encouraging participation of the poor in PES schemes by lowering transaction costs and providing targeted assistance in the form of technical assistance, as well as analyzing the social context in which the PES is implemented (Pagiola 2007).

The above definition of pro-adaptation PES reflects the lessons learned from the PES and poverty debate. Rather than targeting the most vulnerable people as providers of ES, the emphasis is on maximizing synergies and minimizing trade-offs between PES and adaptation. This requires an in-depth assessment of the vulnerability of the various actors and of the natural system within which the PES scheme operates. Given the actor-centered approach of PES, priority should be given to assessing the vulnerability of the actors. However, the vulnerability of the natural system should, as much as possible, also be taken into account. Establishing the vulnerability of the natural system requires the inclusion of natural scientists. Yet their structural approach to the concept of ES has been criticized for failing to take into account the value and needs that local people have regarding ES (Menzel and Teng 2010, Sagoff 2011). This difference between what scientists deem to be important and what local people deem to be important has also been highlighted in the climate change and development literature on the components of vulnerability (Chambers 1989, Smit and Wandel 2006). In order to overcome this discrepancy, all three strands of literature recommend the use of participatory approaches (Chambers 1994, Smit and Wandel 2006, Menzel and Teng 2010) and a greater collaboration between natural and social scientists (Menzel and Teng 2010). When assessing the vulnerability of the various actors and system components of the PES system, a mixture of participatory approaches and ecological modeling and/or climate change modeling should thus be used. This obviously has financial implications.

\section{Financial implications for implementing a pro- adaptation PES}

Just as the question arose in the PES and poverty literature on who should pay for the extra financial resources required for making PES pro-poor (cf Pagiola 2007), a similar problem arises for making PES pro-adaptation, which is compounded by the fact that both concepts are built on different principles. As mentioned above, the concept of PES is rooted in environmental economics and is based on the "beneficiary pays" principle: Buyers in a PES scheme pay for the provision of the ES that would otherwise not be provided by compensating the providers for the costs incurred in providing the service. From an economic point of view, however, buyers are unlikely to pay anything on top of this amount-whether it is for poverty reduction (Pagiola 2007) or for adaptation to climate change-unless they receive a direct benefit. Applying the same principle to adaptation to climate change would mean that those who benefit from adaptation should pay the cost (Farber 2007). In cases where the ES provided reduces the vulnerability of buyers to climate variability and change both principles match. Buyers, however, would not fund adaptation measures for ES providers, as providers would be expected to 
cover their own costs of adaptation under the "beneficiary pays" principle.

In the case of developing countries, applying the "beneficiary pays" principle for adaptation, however, is challenging both for ethical reasons and practical constraints. Despite having contributed little to historic emissions of greenhouse gases, developing countries are regarded as being highly vulnerable to climate change because of their high exposure to physical impacts, their heavy dependence on the agricultural sector (which is particularly sensitive to changes in climate), their high poverty rates, and their limited adaptive capacity (Mertz et al. 2009). Practical constraints relate to their limited adaptive capacity and the insufficiency of current adaptation strategies. Although societies and individuals have always adapted to changing environmental and climatic conditions, this form of autonomous adaptation is unlikely to be an effective and efficient adaptation strategy because of the ad hoc nature through which it is usually implemented (Smit et al. 2001) and the scale of future impacts (Stern 2007). Thus, there is a need for intervention to enhance adaptive capacity (Adger et al. 2003) and for extra financial resources to support developing countries in implementing adaptation measures. From an ethical point of view, the "polluter pays" principle is thus often cited in the context of adaptation finance. This is also partly reflected in the principle of common but differentiated responsibilities of the United Nations Framework Convention on Climate Change (United Nations 1992), as well as Article 4.4 of the convention, which specifies that:

The developed country Parties and other developed Parties included in Annex II shall also assist the developing country Parties that are particularly vulnerable to the adverse effects of climate change in meeting costs of adaptation to those adverse effects.

In current debates on the scale and sources of finances for adaptation, developing countries also maintain that developed countries should assume the greatest share of adaptation finance, given their historic emission of greenhouse gases (Persson et al. 2009).

In terms of financial flows and actors involved, there seems to be a mismatch between the "beneficiary pays" principle under PES and the "polluter pays" principle that is often referred to in the context of finances for adaptation. The extent of this mismatch is probably least pronounced for carbon sequestration in cases where payments flow from developed countries to projects in developing countries. Currently, however, many regulatory carbon markets limit the geographical scale from where offsets can be sourced and the type of land-use activities permitted (Trines 2008, Kohlhoff 2009), thus curtailing the amount of financial flows that could potentially be generated. The voluntary market seems to be less restrictive with regard to forestry offsets coming from developing countries (Neef et al. 2007), but the limited data that are available on the state of forestry/land-use voluntary carbon markets suggest that credits are mainly sourced from the United States, Canada, Australia, and New Zealand rather than Asia, Latin America, or Africa (Hamilton et al. 2008). In the future, however, this may change if international payments for carbon sequestration through the Reducing Emissions from Deforestation and Forest Degradation (REDD) mechanism, as currently discussed under the United Nations Framework Convention on Climate Change, are implemented. REDD can be regarded as a multi-level PES scheme, where payments are made at the international level for reduced emissions from deforestation and forest degradation (Angelsen and WertzKanounnikoff 2008). Rough estimates suggest that as much as 25-50 million low-income households in developing countries could benefit from carbon markets by 2030 (Milder et al. 2010).

Even though the mismatch between the "polluter pays" and "beneficiary pays" principles is less in the case of payments for carbon sequestration, there is still the question of whether buyers would be willing to pay extra financial resources for adaptation to climate change of ES providers. For the voluntary carbon market, where buyers already show an interest in economic and social co-benefits (FAO 2007) and where the main motivation for buying is corporate social responsibility and goodwill (Hamilton et al. 2010), there might well be the potential for such an increased willingness to pay. On the other hand, the long distance between buyers and providers could pose problems, with buyers probably knowing little about the factors that shape vulnerability at the local level, which could inhibit their willingness to pay. Lohmann (2008), for example, maintains that this distance contributes to ignorance about the complex interactions of biology, physics, and politics of carbon projects, with buyers having little information about the local implications of their purchase. For the private sector for watershed markets, where the main motivation is to secure the provision of ES, there might be less potential, especially as engaging the private sector in PES schemes is already proving to be a challenge (Geoghegan 2005, Waage et al. 2007, Porras et al. 2008). The fact that these actors are more directly dependent on ES and that the distance between buyers and providers is less may, however, motivate them to provide extra financial resources.

It is thus likely that extra financial resources in addition to those generated by ES buyers are required in order to make PES pro-poor and pro-adaptation. Just as in the case of propoor PES, donor funds could be another source for this, especially as adaptation to climate change is rising fast on the agenda of donors.

Much of the extra financial resources for making PES propoor and pro-adaptation would probably be required as upfront costs in the scoping phase of PES projects in order to identify interlinkages between vulnerability to climate change 
Table 1. Instruments and recommendations for making PES pro-poor and pro-adaptation

\begin{tabular}{lll}
\hline \hline & Instruments and recommendations & PES phase \\
\hline $\begin{array}{lll}\text { Identification of synergies and trade-offs } \\
\text { between PES and adaptation }\end{array}$ & $\begin{array}{l}\text { Participatory vulnerability assessment to identify adaptive } \\
\text { capacity, adaptation strategies, and dependence on ecosystem }\end{array}$ & Scoping/Monitoring \\
& $\begin{array}{l}\text { services of PES actors } \\
\text { Ecological and climate impact modeling to identify vulnerability } \\
\text { of the natural system toward climate variability and change and }\end{array}$ & Scoping/Monitoring \\
& trade-offs between enhancing different ES for different purposes
\end{tabular}

Maximizing synergies and minimizing trade-offs

\begin{abstract}
Choice experiments to assess whether payments can be made to finance adaptation measures rather than being made in cash Assess how far these can be made at the community level

Exploit possibility of targeting payments to ES providers during vulnerable periods within a year

Use institutional structures set up during a PES to increase awareness about climate variability and change and appropriate adaptation measures

Make sure these are also accessible to non-PES participants to avoid erosion of social capital

In cases where measures introduced under the PES are likely to increase vulnerability to climate variability and change, ensure that counteracting mechanisms are put in place (e.g., providing an alternative source of fodder where access to grazing land is restricted)

Ensure that payments made to ES providers are higher than opportunity costs
\end{abstract}

Scoping/Implementation

Scoping/Implementation

Scoping/Implementation

Scoping/Implementation

Implementation

Implementation

Implementation/ Monitoring and ES provision, both of the natural as well as the social system. In addition, extra financial resources might be needed to cover the implementation of adaptation measures should the finances generated under the PES scheme not be enough. There could thus be a division of labor, with donors and other sources of adaptation finance covering these costs, whereas the ES buyers would cover the actual implementation costs. Many donors are already heavily involved in supporting PES schemes, especially in the early stages of the project. The International Fund for Agricultural Development (IFAD), for example, has supported the RUPES (Rewarding Upland Poor for the Environment Services They Provide) program in Asia and has recently started a similar program in Africa (IFAD 2011).

Table 1 summarizes different instruments and recommendations for designing and implementing a pro-adaptation PES according to the different phases of a PES project.

\section{CONCLUSION}

This article has established the conceptual links between PES and adaptation to climate variability and change and suggested ways of making PES pro-poor and pro-adaptation. A proadaptation PES maximizes synergies and minimizes trade-offs between PES and adaptation. Given that both adaptation and the provision of ES are highly context and place specific, this requires strong interdisciplinary research at the local level, taking into account the impacts of climate variability and change, the adaptive capacity of the various system components, as well as an analysis of adaptation strategies. Some of the research needs have already been identified in the current literature on PES (e.g., synergies and trade-offs between different ES, further evidence on the impacts of PES on livelihoods) but become even more urgent in the context of climate variability and change in order to ensure that PES schemes do not contribute to maladaptation.

Research needs can be differentiated for existing and new PES schemes. For existing PES schemes that have been in progress for some time, more needs to be known about how the PES has influenced the ability of the various actors to deal with climate variability and change. In what way have PES contributed to an increased adaptive capacity of the different actors? Are there cases where the adaptive capacity has been reduced as a result of PES? How much have climate change considerations influenced the willingness of PES buyers to pay for the provision of ES? What can be learned from these cases for the design and implementation of new PES schemes?

For the establishment of future PES schemes: What is the adaptive capacity of the different actors involved in the PES scheme? What options exist to enhance adaptive capacity and provide incentives for adaptation strategies through PES? Are the finances generated under PES enough to implement the PES and to foster adaptation? What institutional structures are 
needed at what levels in order to further promote the integration of PES and adaptation to climate change?

Although much still needs to be learned about the integration of PES and adaptation to climate change, there is also an opportunity for mutual learning across disciplines (social sciences and natural sciences) and stakeholders as well as for scaling up PES schemes in the developing world. The possibility that PES could contribute to poverty reduction has initiated a flurry of interest among development practitioners, donors, and academia, with an ever-increasing amount of literature emerging on this topic and new projects emerging in different parts of the world. It is hoped that a similar interest will also be generated in the context of PES and adaptation to climate change in order to advance our knowledge and strive toward the greater goal of sustainable development in an increasingly uncertain world.

Responses to this article can be read online at: http://www.ecologyandsociety.org/vol17/iss1/art11/ responses/

\section{Acknowledgments:}

An earlier version of this article was presented at the 11th Biennial Conference of the International Society for Ecological Economics (ISEE) in Oldenburg in 2010, and I am grateful for the feedback received from the participants at the conference. I would also like to thank Dr. Imme Scholz as well as two anonymous reviewers for their very constructive and detailed comments and suggestions on how to improve an earlierdraft of this article. I acknowledge the financial support received from the German Federal Ministry for Economic Cooperation and Development (BMZ), which has funded this research.

\section{LITERATURE CITED}

Adger, W. N. 2006. Vulnerability. Global Environmental Change 16:268-281. http://dx.doi.org/10.1016/j.gloenvcha.2 $\underline{006.02 .006}$

Adger, W. N., S. Agrawala, M. M. Q. Mirza, K. O’Brien, J. Pulhin, R. Pulwarty, B. Smit, and K. Takahashi. 2007. Assessment of adaptation practices, options, constraints and capacity. Pages 717-743 in M. L. Parry, O. F. Canziani, J. P. Palutikof, P. J. van der Linden, and C. E. Hanson, editors. Climate Change 2007: Impacts, Adaptation and Vulnerability. Contribution of Working Group II to the Fourth Assessment Report of the Intergovernmental Panel on Climate Change. Cambridge University Press, Cambridge, UK.

Adger, W. N., N. Brooks, G. Bentham, M. Agnew, and S. Eriksen. 2004. New indicators of vulnerability and adaptive capacity. Technical Report 7, Tyndall Centre for Climate
Change Research, University of East Anglia, Norwich, UK.

Adger, W. N., S. Huq, K. Brown, D. Conway, and M. Hulme. 2003. Adaptation to climate change in the developing world. Progress in Development Studies 3(3):179-195. http://dx.doi. org/10.1191/1464993403ps060oa

Angelsen, A., and S. Wertz-Kanounnikoff. 2008. What are the key design issues for REDD and the criteria for assessing options. Pages 11-22 in A. Angelsen, editor. Moving ahead with REDD: issues, options and implications. Center for International Forestry Research, Bogor, Indonesia.

Brooks, N. 2003. Vulnerability, risk and adaptation: a conceptual framework. Working Paper 38, Tyndall Centre for Climate Change Research, University of East Anglia, Norwich, UK.

Bruijnzeel, L. A. 2004. Hydrological functions of tropical forests: not seeing the soil for the trees? Agriculture, Ecosystems and Environment 104(1):185-228. http://dx.doi.o rg/10.1016/j.agee.2004.01.015

Bulte, E. H., L. Lipper, R. Stringer, and D. Zilberman. 2008. Payments for ecosystem services and poverty reduction: concepts, issues, and empirical perspectives. Environment and Development Economics 13:245-254. http://dx.doi.org/10.1017/ $\underline{\mathrm{S} 1355770 \mathrm{X} 08004348}$

Burton, I., S. Huq, B. Lim, O. Pilifosova, and E. L. Schipper. 2002. From impacts assessment to adaptation priorities: the shaping of adaptation policy. Climate Policy 2:145-159.

Burton, I., B. Lim, and S. Huq. 2001. Adaptation policy framework. United Nations Development Programme (UNDP), New York, New York, USA.

Caplow, S., P. Jagger, K. Lawlor, and E. Sills. 2011. Evaluating land use and livelihood impacts of early forest carbon projects: lessons for learning about REDD+. Environmental Science and Policy 14(2):152-167. http://dx.d oi.org/10.1016/j.envsci.2010.10.003

Carroll, N., and M. Jenkins. 2008. The matrix: mapping ecosystem service markets. Ecosystem Marketplace. [online] URL: http://ecosystemmarketplace.com/pages/article.news.php? component_id=5917\&component_version_id=8762\&language_ $\mathrm{id}=12$

Chambers, R. 1989. Editorial introduction: vulnerability, coping and policy. IDS Bulletin 20(2):1-7. http://dx.doi.org/1 $\underline{0.1111 / j .1759-5436.2006 . t b 00284 . \mathrm{x}}$

Chambers, R. 1994. Participatory rural appraisal (PRA): challenges, potentials and paradigm. World Development 22 (10):1437-1454. http://dx.doi.org/10.1016/0305-750X(94)90030-2

Chan, K. M. A., M. R. Shaw, D. R. Cameron, E. C. Underwood, and G. C. Daily. 2006. Conservation planning for ecosystem 
services. PLoS Biology 4(11):e379. http://dx.doi.org/10.1371/ journal.pbio.0040379

Corbera, E., and K. Brown. 2010. Offsetting benefits? Analyzing access to forest carbon. Environment and Planning A 42(7):1739-1761. http://dx.doi.org/10.1068/a42437

Corbera, E., C. Soberanis, and K. Brown. 2009. Institutional dimensions of payments for ecosystem services: an analysis of Mexico's carbon forestry programme. Ecological Economics 68(3):743-761. http://dx.doi.org/10.1016/j.ecolec on.2008.06.008

Dang, H. H., A. Michaelowa, and D. D. Tuan. 2003. Synergy of adaptation and mitigation strategies in the context of sustainable development: the case of Vietnam. Climate Policy 3S1:81-96. http://dx.doi.org/10.1016/j.clipol.2003.10.006

Engel, S., S. Pagiola, and S. Wunder. 2008. Designing payments for environmental services in theory and practice: an overview of the issues. Ecological Economics 65(4):663674. http://dx.doi.org/10.1016/j.ecolecon.2008.03.011

Eriksen, S. E. H., R. J. T. Klein, K. Ulsrud, L. O. Naess, and K. O'Brien. 2007. Climate change adaptation and poverty reduction: key interactions and critical measures. Report prepared for the Norwegian agency for development cooperation (Norad). GECHS, Report 1, University of Oslo, Oslo, Norway.

Farber, D. A. 2007. Adapting to climate change: who should pay. Journal of Land Use 23(1):1-38.

Fisher, B., R. K. Turner, and P. Morling. 2009. Defining and classifying ecosystem services for decision making. Ecological Economics 68(3):643-653. http://dx.doi.org/10.10 $\underline{\text { 16/j.ecolecon.2008.09.014 }}$

Food and Agriculture Organization (FAO). 2007. The State of Food and Agriculture. Paying Farmers for Environmental Services. Agriculture Series No. 38, FAO of the United Nations, Rome, Italy.

Füssel, H. M. 2007. Vulnerability: a generally applicable conceptual framework for climate change research. Global Environmental Change 17:155-167. http://dx.doi.org/10.1016/ j.gloenvcha.2006.05.002

Geoghegan, T. 2005. Challenges to establishing markets for watershed services: learning from country diagnostics. International Institute for Environment and Development, London, UK.

Giddings, B., B. Hopwood, and G. O'Brien. 2002. Environment, economy and society: fitting them together into sustainable development. Sustainable Development 10 (4):187-196. http://dx.doi.org/10.1002/sd.199

Gómez-Baggethun, E., R. de Groot, P. L. Lomas, and C. Montes. 2010. The history of ecosystem services in economic theory and practice: from early notions to markets and payment schemes. Ecological Economics 69:1209-1218. http://dx.doi. org/10.1016/j.ecolecon.2009.11.007

Hamilton, K., M. Sjardin, T. Marcello, and G. Xu. 2008. Forging a Frontier: State of the Voluntary Markets 2008. Ecosystem Market Place and New Carbon Finance, New York, New York, and Washington, D.C., USA.

Hamilton, K., M. Sjardin, M. Peters-Stanley, and T. Marcello. 2010. Building Bridges: State of the Voluntary Carbon Markets 2010. Ecosystem Marketplace and Bloomberg New Energy Finance, Washington, D.C. and New York, New York, USA.

Horstmann, B. 2008. Framing adaptation to climate change: a challenge for building institutions. Discussion Paper 23/2008, German Development Institute / Deutsches Institut für Entwicklungspolitik (DIE), Bonn, Germany.

International Fund for Agricultural Development (IFAD). 2011. RUPES: rewarding poor people for environmental services. IFAD, Rome, Italy.

Klein, R. J. T. 2010. Mainstreaming climate adaptation into development. Pages 35-52 in A. Ansohn and B. Pleskovi, editors. Climate governance and development. World Bank, Washington, D.C., USA.

Kohlhoff, L. A. 2009. The state of the international forest carbon market. Master' project. Duke University, Durham, North Carolina, USA.

Kosoy, N., and E. Corbera. 2010. Payments for ecosystem services as commodity fetishism. Ecological Economics 69 (6):1228-1236. http://dx.doi.org/10.1016/j.ecolecon.2009.11.002

Kosoy, N., M. Martinez-Tuna, R. Muradian, and J. MartinezAlier. 2007. Payments for environmental services in watersheds: insights from a comparative study of three cases in Central America. Ecological Economics 61:446-455. http: //dx.doi.org/10.1016/j.ecolecon.2006.03.016

Landell-Mills, N. and I. T. Porras. 2002. Silver bullet or fools' gold? A global review of markets for forest environmental services and their impact on the poor. Instruments for sustainable private sector forestry series, International Institute for Environment and Development, London, UK.

Locatelli, B., M. Kanninen, M. Brockhaus, C. J. P. Colfer, D. Murdiyarso, and H. Santoso. 2008. Facing an uncertain future: how forests and people can adapt to climate change. Forest Perspectives No. 5, Center for International Forestry Research (CIFOR), Bogor, Indonesia.

Locatelli, B., and R. Vignola. 2009. Managing watershed services of tropical forests and plantations: can meta-analyses help? Forest Ecology and Management 258(9):1864-1870. http://dx.doi.org/10.1016/j.foreco.2009.01.015 
Lohmann, L. 2008. Carbon trading, climate justice and the production of ignorance: ten examples. Development 51:359365. http://dx.doi.org/10.1057/dev.2008.27

McCarthy, J., O. Canziani, N. A. Leary, and D. Dokken, editors. 2001. Climate Change 2001: Impacts, Adaptation, and Vulnerability. Contriubution of the Working Group II to the Third Assessment Report of the Intergovernmental Panel on Climate Change, Cambridge University Press, Cambridge, UK.

McGray, H., A. Hammil, R. Bradley, L. Schipper, and J. E. Parry. 2007. Weathering the storm. Options for framing adaptation and development. World Resources Institute, Washington, D.C., USA.

Menzel, S., and J. Teng. 2010. Ecosystem services as a stakeholder-driven concept for conservation science. Conservation Biology 24(3):907-909. http://dx.doi.org/10.1111/ j.1523-1739.2009.01347.x

Mertz, O., K. Halsnæs, J. E. Olesen, and K. Rasmussen. 2009. Adaptation to climate change in developing countries. Environmental Management 43(5):743-752. http://dx.doi.org /10.1007/s00267-008-9259-3

Milder, J. C., S. J. Scherr, and C. Bracer. 2010. Trends and future potential of payment for ecosystem services to alleviate rural poverty in devaloping countries. Ecology and Society 15 (2):4. [online] URL: http:www.ecologyandsociety.org/vol15/ iss2/art4.

Millennium Ecosystem Assessment. 2005. Ecosystems and human well-being: synthesis. Island Press, Washington, D.C., USA.

Muradian, R., E. Corbera, U. Pascual, N. Kosoy, and P. H. May. 2010. Reconciling theory and practice: an alternative conceptual framework for understanding payments for environmental services. Ecological Economics 69(6):12021208. http://dx.doi.org/10.1016/j.ecolecon.2009.11.006

Neef, T., L. Eichler, I. Deecke, and J. Fehse. 2007. Update on markets for forestry offsets. Tropical Agricultural Research and Higher Education Center, Turrialba, Costa Rica.

Pagiola, S. 2007. Guidelines for "Pro-Poor" Payments for Environmental Services. World Bank, Washington, D.C., USA.

Pagiola, S. 2008. Payments for environmental services in Costa Rica. Ecological Economics 65:712-724. http://dx.doi. org/10.1016/j.ecolecon.2007.07.033

Pagiola, S., A. Arcenas, and G. Platais. 2005. Can payments for environmental services help reduce poverty? An exploration of the issues and the evidence to date from Latin America. World Development 33(2):237-253. http://dx.doi.or g/10.1016/j.worlddev.2004.07.011
Parry, M. L., O. F. Canziani, and J. Palutikof. 2007. Climate Change 2007: impacts, adaptation and vulnerability. Contribution of Working Group II to the fourth assessment report of the Intergovernmental Panel on Climate Change, Cambridge University Press, Cambridge, UK.

Pattanayak, S. K., S. Wunder, and P. J. Ferraro. 2010. Show me the money: do payments supply environmental services in developing countries? Review of Environmental Economics and Policy 4(2):254-274. http://dx.doi.org/10.1093/reep/req006

Persson, Å., R. J. T. Klein, C. K. Siebert, A. Atteridge, B. Müller, J. Hoffmaister, M. Lazarus, and T. Takama. 2009. Adaptation finance under a Copenhagen agreed outcome. Stockholm Environment Institute, Stockholm, Sweden.

Pielke, R. A. 1998. Rethinking the role of adaptation in climate policy. Global Environmental Change 8(2):159-170. http://d x.doi.org/10.1016/S0959-3780(98)00011-9

Porras, I., M. Grieg-Gran, and N. Neves. 2008. All that glitters. A review of payments for watershed services in developing countries. Natural Resource Issues No. 11, International Institute for Environment and Development, London, UK.

Ravnborg, H. M., M. G. Damsgaard, and K. Raben. 2007. Payments for ecosystem services-issues and pro-poor opportunities for development assistance. Danish Institute for International Studies, Copenhagen, Denmark.

Redford, K. H., and W. M. Adams. 2009. Payment for ecosystem services and the challenge of saving nature. Conservation Biology 23(4):785-787. http://dx.doi.org/10.1111/ j.1523-1739.2009.01271.x

Sagoff, M. 2011. The quantification and valuation of ecosystem services. Ecological Economics 70(3):497-502. http://dx.doi.org/10.1016/j.ecolecon.2010.10.006

Schneider, S. H., S. Semenov, A. Patwardhan, I. Burton, C. H. D. Magadza, M. Oppenheimer, A. B. Pittock, A. Rahman, J. B. Smith, A. Suarez, and F. Yamin. 2007. Assessing key vulnerabilities and the risk from climate change. Pages 779810 in M. L. Parry, O. F. Canziani, J. P. Palutikof, P. J. van der Linden, and C. E. Hanson, editors. Climate Change 2007: Impacts, Adaptation and Vulnerability. Contribution of Working Group II to the Fourth Assessment Report of the Intergovernmental Panel on Climate Change, Cambridge University Press, Cambridge, UK.

Smit, B., O. Pilifosova, I. Burton, B. Challenger, S. Huq, R. J. T. Klein, and G. Yohe. 2001. Adaptation to Climate Change in the Context of Sustainable Development and Equity. Pages 877-912 in J. J. McCarthy, O. Canziani, N. A. Leary, D. J. Dokken, and K. S. White, editors. Climate Change 2001: Impacts, Adaptation and Vulnerability. Cambridge University Press, Cambridge, UK. 
Smit, B., and J. Wandel. 2006. Adaptation, adaptive capacity and vulnerability. Global Environmental Change 16:282-292. http://dx.doi.org/10.1016/j.gloenvcha.2006.03.008

Smith, J. B., H. J. Schellnhuber, M. M. Q. Mirza, S. Fankhauser, R. Leemans, E. Lin, L. Ogallo, B. Pittock, R. G. Richels, C. Rosenzweig, U. Safriel, R. S. J. Tol, J. Weyant, and G. Yohe. 2001. Vulnerability to climate change and reasons for concern: a synthesis. Pages 913-967 in J. McCarthy, O. F. Canziani, N. A. Leary, D. J. Dokken, and K. S. White, editors. Climate Change 2001: Impacts, Adaptation, and Vulnerability. Cambridge University Press, Cambridge, UK.

Sommerville, M. M., J. P. G. Jones, and E. J. Milner-Gulland. 2009. A revised conceptual framework for payments for environmental services. Ecology and Society 14(2):34. [online] URL: http:www.ecologyandsociety.org/vol14/iss2/art34

Stern, N. 2007. The economics of climate change: the Stern Review. Cambridge University Press, Cambridge, UK.

Suyanto, S., N. Khususiyah, and B. Leimona. 2007. Poverty and environmental services: case study in Way Besai watershed, Lampung Province, Indonesia. Ecology and Society 12(2):13. [online] URL: http:www.ecologyandsociety. org/vol12/iss2/art13.

Tacconi, L., S. Mahanty, and H. Suich. 2010a. Forests, payments for environmental services and livelihoods. Pages 1-25 in L. Tacconi, S. Mahanty, and H. Suich, editors. Payments for environmental services, forest conservation and climate change. Livelihoods in the REDD? Edward Elgar Publishing, Cheltenham, UK.

Tacconi, L., S. Mahanty, and H. Suich. 2010b. PES schemes' impacts on livelihoods and implications for REDD activities. Pages 244-260 in L. Tacconi, S. Mahanty, and H. Suich, editors. Payments for Environmental Services, Forest Conservation and Climate Change: Livelihoods in the REDD? Edward Elgar, Cheltenham, UK.

Tognetti, S., G. Mendoza, D. Southgate, B. Aylward, and L. Garcia. 2003. Assessing the Effectiveness of Payment Arrangements for Watershed Ecosystem Services (PWES). Third Latin American Congress on Watershed Management, Regional Forum on Payments for Environmental Services. 912 June 2003, Arequipa, Perú.

Trines, E. 2008. History and Context of LULUCF in the Climate Regime. Pages 33-42 in C. Streck, R. O'Sullivan, T. Janson-Smith, and R. G. Tarasofsky, editors. Climate change and forests. Emerging Policies and market opportunities. Royal Institute of International Affairs, London, UK.

Turner, B. L., R. E. Kasperson, P. A. Matson, J. J. McCarthy, R. W. Corell, L. Christemsem, N. Eckley, J. X. Kasperson, A.
Luers, M. L. Martello, C. Polsky, A. Pulsipher, and A. Schiller. 2003. A framework for vulnerability analysis in sustainability science. Proceedings of the National Academy of Science 100 (14):8074-8079. http://dx.doi.org/10.1073/pnas.1231335100

United Nations. 1992. United Nations Framework Convention on Climate Change. United Nations, New York, New York, USA. [online] URL: http://unfccc.int/resource/docs/convkp/c onveng.pdf.

van de Sand, I. 2004. Assessing the use of environmental service payments as a potential adaptation strategy to climate change in Cidanau watershed, Banten, Indonesia. Thesis, Imperial College London, London, UK.

Waage, S., I. Mulder, K. ten Kate, S. Scherr, J. Roberts, A. Hawn, K. Hamilton, R. Bayon, and N. Carroll. 2007. Investing in the future: an assessment of private sector demand for engaging in markets and payments for ecosystem services. PESAL Papers Series 2, FAO, Rome, Italy and Forest Trends, Washington D.C., USA.

Willetts, E. 2008. Watershed Payments for Ecosystem Services and Climate Change Adaptation. Thesis, Duke University, Durham, North Carolina, USA.

Wunder, S. 2005. Payments for environmental services: some nuts and bolts. Center for International Forestry Research (CIFOR), Bogor, Indonesia.

Wunder, S. 2006. Are Direct Payments for Environmental Services Spelling Doom for Sustainable Forest Management in the Tropics? Ecology and Society 11(2):23. [online] URL: http:www.ecologyandsociety.org/vol11/iss2/art23.

Wunder, S. 2008. Payments for environmental services and the poor: concepts and preliminary evidence. Environment and Development Economics 13:279-297. http://dx.doi.org/10.1017/ $\underline{\mathrm{S} 1355770 \mathrm{X} 08004282}$

Wunder, S., S. Engel, and S. Pagiola. 2008. Taking stock: a comparative analysis of payments for environmental services programs in developed and developing countries. Ecological Economics 65(4):834-852. http://dx.doi.org/10.1016/j.ecolec on.2008.03.010

Zelli, F. 2010. Technologies for Adaptation to Climate Change: a Stepchild of International Climate Negotiations. 51st Annual Conference of the International Studies Association. 17-20 February 2010, New Orleans, USA. 